\title{
IVIG Reduced Vascular Oxidative Stress in Patients With Kawasaki Disease
}

\author{
Shinichi Takatsuki, MD; Yuka Ito, MD; Daiji Takeuchi, MD; Hiroshi Hoshida, MD; \\ Tomotaka Nakayama, MD; Hiroyuki Matsuura, MD; Tsutomu Saji, MD
}

\begin{abstract}
Background: Oxidative stress (OS) contributes to the acute phase of Kawasaki disease (KD) in a manner that is as yet unknown. In the present study OS in the acute phase of KD was investigated by measuring urinary 8-isoprostaglandin $\mathrm{F} 2 \alpha$ (8-iso-PG) and evaluating its correlation to the efficacy of intravenous immunoglobulin (IVIG) administration.

Methods and Results: The 62 patients with acute phase of KD were enrolled, as well as 20 healthy children (HC) and 20 with acute febrile illness (FI). Urinary samples were obtained before and after administration of IVIG. The HC and FI groups also had inflammatory markers evaluated at the same time. The 8-iso-PG was significantly elevated in the $62 \mathrm{KD}$ patients $(719 \pm 335 \mathrm{pg} / \mathrm{mg} \mathrm{Cr})$ without IVIG administration compared with those with FI $(583 \pm 213 \mathrm{pg} / \mathrm{mg} \mathrm{Cr})$ as well as $\mathrm{HC}(443 \pm 288 \mathrm{pg} / \mathrm{mg} \mathrm{Cr})(\mathrm{P}<0.01) .40$ patients were given 3 different regimens of IVIG: 16 received $2 \mathrm{~g} / \mathrm{kg}$ for 1 day; 17 received $1 \mathrm{~g} / \mathrm{kg}$ for 1 day; 7 received $400 \mathrm{mg} \cdot \mathrm{kg}^{-1} \cdot \mathrm{day}^{-1}$ for 5 days. All regimens of IVIG reduced the 8-iso-PG level at 7 days after initiation.

Conclusions: OS provokes vasculitis in KD, the activation of which was reduced by IVIG. The urinary level of 8iso-PG is a useful marker of the effectiveness of IVIG in the acute phase of KD. (Circ J 2009; 73: 1315-1318)
\end{abstract}

Key Words: Intravenous immunoglobulin; 8-iso-prostaglandin F2 $\alpha$; Kawasaki disease; Oxidative stress

$\mathbf{O}$ xidative stress (OS) plays an important role in vascular diseases. Endothelial dysfunction activates the pathway that leads to elevated OS! In particular, oxidative damage occurs when the delicate balance between pro- and antioxidant molecules, which act against free radical injury, is upset. This balance may be destroyed by certain risk factors; for example, atherosclerosis, hypertension, hyperlipidemia, diabetes and cigarette smoking?-6

The 8-isoprostaglandin F2 $\alpha$ (8-iso-PG) is a nonenzymatic oxidation product of arachidonic acid and is widely recognized as a reliable marker of lipid peroxidation both in vitro and in vivo $3,4,7$ Enhanced endothelial dysfunction, as reflected by increased 8-iso-PG excretion, has been reported previously? -5

Kawasaki disease (KD) is a systemic vasculitis and an acute febrile illness (FI) in children. Recent studies have shown activation of the immune system is involved and multiple factors are likely to cause the pathologic changes seen in $\mathrm{KD}^{8-11}$ How OS contributes to the acute phase of $\mathrm{KD}$ is as yet unknown.

In the present study, we investigated OS in the acute phase of KD by measuring urinary 8-iso-PG and evaluated its correlation to the efficacy of intravenous immunoglobulin (IVIG) treatment.
(Received August 29, 2007; revised manuscript received February 2, 2009; accepted February 18, 2009; released online May 13, 2009) Pediatrics, Toho University Omori Medical Center, Tokyo, Japan Mailing address: Shinchi Takatsuki, MD, Pediatrics, Toho University Omori Medical Center, 6-11-1 Omorinishi, Ota-ku, Tokyo 143-8541, Japan. E-mail: tekeshin0621@msn.com

All rights are reserved to the Japanese Circulation Society. For permissions, please e-mail: cj@j-circ.or.jp

\section{Methods}

\section{Patients}

All subjects of this study were typical KD patients admitted to Toho University Hospital between March 2002 and September 2004. They were given IVIG $(1-2 \mathrm{~g} / \mathrm{kg})$ therapy in the acute phase: 62 patients ( 37 boys, 25 girls, median age: 4 years, range: 2 months to 11 years) were enrolled. None of the patients had other disorders, such as infection, collagen disease or congenital heart disease. We also studied 20 healthy children (HC, median age: 4 years, range: $1-11$ years) and 20 patients with an acute FI such as viral pharyngitis and tonsillitis (median age: 5 years, range: 1-10 years). Informed consent was given by the parents of the patients participating in the study.

\section{Biochemical Measurements}

Urinary 8-iso-PG was measured by enzyme immunoassay and the concentration was corrected by urinary creatinine concentration. The samples were obtained before and after IVIG administration. In the HC and FI groups inflammatory markers such as C-reactive protein (CRP), white blood cell (WBC) count, neutrophil count, albumin level and erythrocyte sedimentation rate (ESR) were measured at the same time. Echocardiography was performed in the patients in the acute phase of KD.

\section{Statistical Analysis}

Differences between continuous variables were evaluated by $\mathrm{t}$-test. The data for each group were analyzed using ANOVA. The relationship between 2 different parameters was obtained by simple regression analysis. A P-value $<0.05$ was considered statistically significant. 
Table. Clinical Characteristics of Patients and Controls

\begin{tabular}{lcccc}
\hline & KD group & FI group & HC group & P value \\
\hline $\mathrm{n}$ & 62 & 20 & 20 & NS \\
Age (median) & 2 months-11 years (4 years) & $1-10$ years $(5$ years $)$ & $1-11$ years (4 years) & NS \\
M/F & $37 / 25$ & $12 / 8$ & $10 / 10$ & NS \\
\hline
\end{tabular}

KD, Kawasaki disease; FI, febrile illness; HC, healthy children.

\section{Results}

\section{Clinical Characteristics of Patients and Controls}

The baseline characteristics of the patients and control subjects are detailed in Table. No significant differences between patients with $\mathrm{KD}$, FI and $\mathrm{HC}$ were found. Two patients in the KD group had coronary artery abnormalities

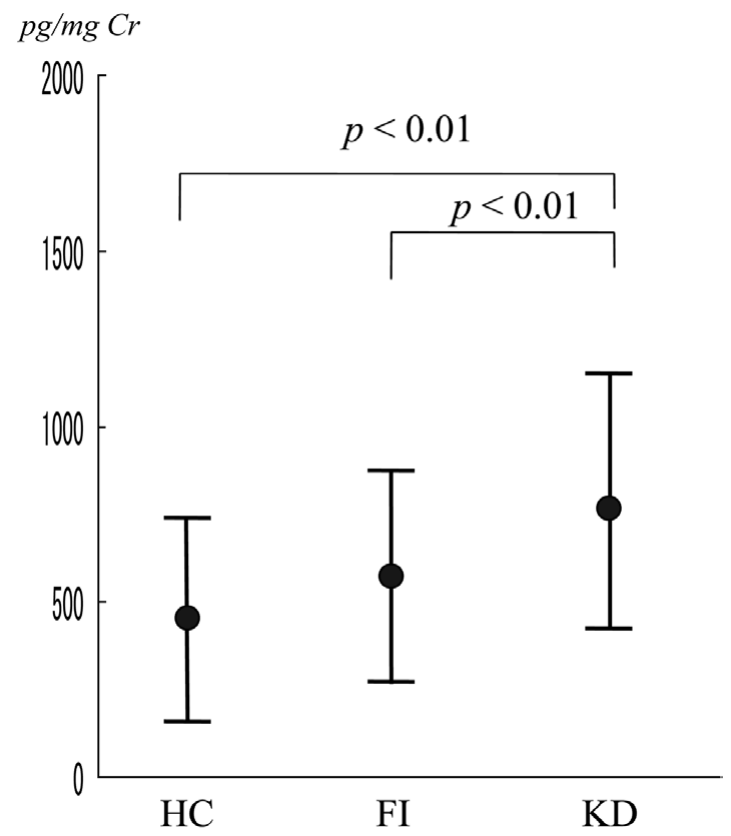

Figure 1. The 8-iso-prostaglandin $\mathrm{F} 2 \alpha$ in patients with Kawasaki disease (KD) or febrile illness (FI) and in healthy controls. Gray zone shows the normal range in children. $\mathrm{HC}$, healthy children.
( 1 had a coronary artery lesion (CAL), 1 had coronary artery dilatation).

\section{8-iso-PG Levels in the KD and Control Groups}

The 8-iso-PG was significantly elevated in the $62 \mathrm{KD}$ patients $(719 \pm 335 \mathrm{pg} / \mathrm{mg} \mathrm{Cr}$ ) before IVIG administration compared with the 20 patients with FI $(583 \pm 213 \mathrm{pg} / \mathrm{mg} \mathrm{Cr})$ and the $20 \mathrm{HC}(443 \pm 288 \mathrm{pg} / \mathrm{mg} \mathrm{Cr})(\mathrm{P}<0.011$-way ANOVA) (Figure 1). The normal value of 8 -iso-PG in children is $<650 \mathrm{pg} / \mathrm{mg} \mathrm{Cr}$.

\section{8-iso-PG and Inflammatory Parameters}

We evaluated inflammatory parameters such as CRP, albumin, WBC count, neutophil count and ESR, but there were no significant correlations between 8-iso-PG and any of these.

\section{8-iso-PG Levels in the Acute Phase of KD After IVIG Therapy}

We evaluated 8-iso-PG levels in 40 patients with acute $\mathrm{KD}$ before and after IVIG treatment. The 8-iso-PG levels at 7 days after a single administration of IVIG were significantly decreased compared with before treatment (707士 $356 \mathrm{pg} / \mathrm{mg}$ Cr vs $426 \pm 214 \mathrm{pg} / \mathrm{mg} \mathrm{Cr} ; \mathrm{P}<0.01$ paired t-test) (Figure 2). The 8-iso-PG levels before IVIG administration tended to be decreased compared with after 14 days (707士 $356 \mathrm{pg} / \mathrm{mg} \mathrm{Cr}$ vs $556 \pm 324 \mathrm{pg} / \mathrm{mg} \mathrm{Cr} ; \mathrm{P}=0.05$ paired t-test).

We also evaluated the 8-iso-PG levels in 40 patients given 3 different regimens of IVIG: 16 patients received $2 \mathrm{~g} / \mathrm{kg}$ for 1 day, 17 patients received $1 \mathrm{~g} / \mathrm{kg}$ for 1 day and 7 patients received $400 \mathrm{mg} \cdot \mathrm{kg}^{-1} \cdot \mathrm{day}^{-1}$ for 5 days. All treatment regimens of IVIG reduced the 8-iso-PG level at 7 days after administration. The 8-iso-PG levels before IVIG administration were not significant different between the 3 regimens. The 8-iso-PG tended to decrease in the patients

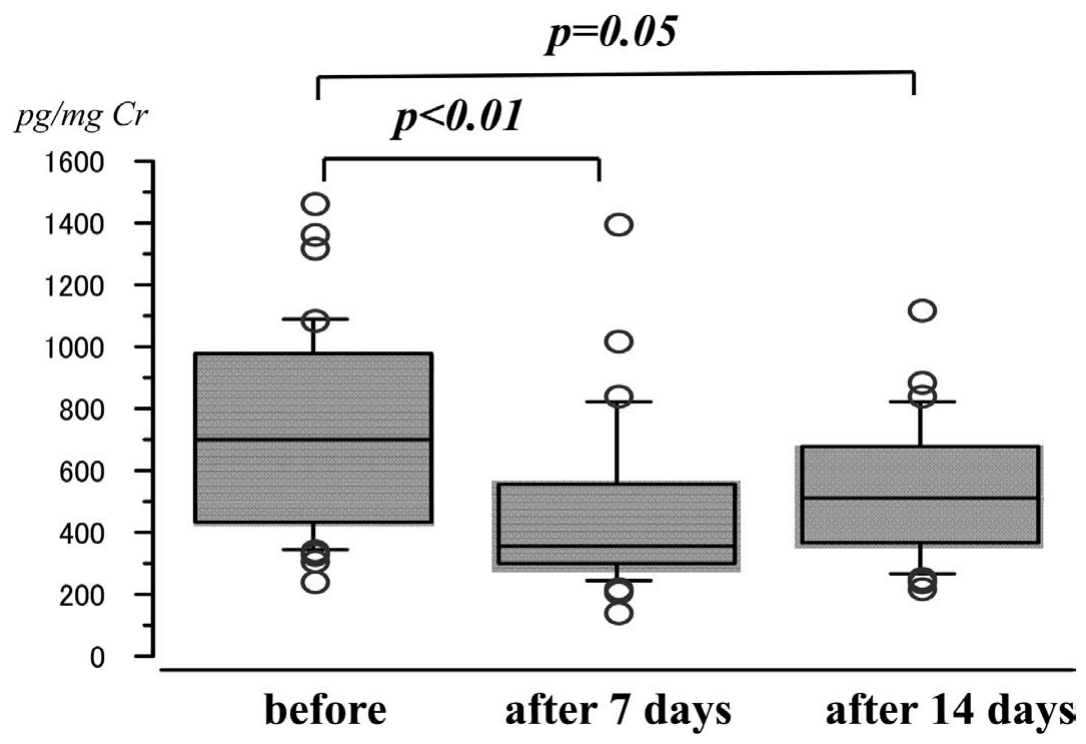

Figure 2. The 8-iso-prostaglandin F2 $\alpha$ levels before and after intravenous immunoglobulin therapy ( 7 and 14 days). 


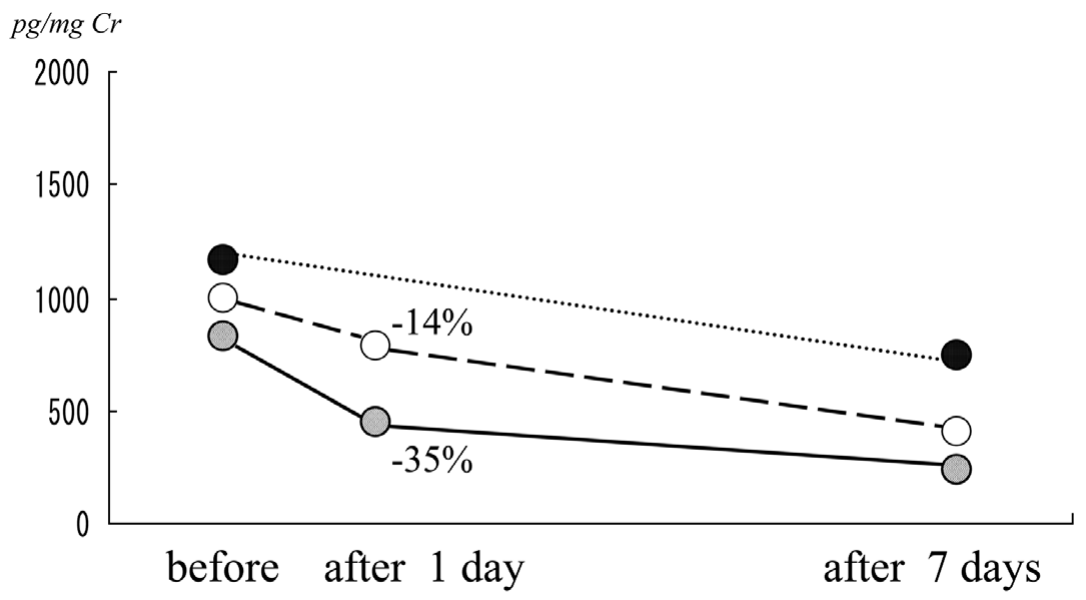

Figure 3. The 8-iso-prostaglandin $\mathrm{F} 2 \alpha$ levels in patients given 3 regimens of intravenous immunoglobulin. (•) $400 \mathrm{mg} \cdot \mathrm{kg}^{-1} \cdot \mathrm{day}^{-1}$ for 5 days, $(\bigcirc) 1 \mathrm{~g} / \mathrm{kg}$ for 1 day (O) $2 \mathrm{~g} / \mathrm{kg}$ for 1 day.

with the single $2 \mathrm{~g} / \mathrm{kg}$ administration compared with those who received $1 \mathrm{~g} / \mathrm{kg}$ of IVIG infusion for 1 day $(1 \mathrm{~g} / \mathrm{kg}$ vs $2 \mathrm{~g} / \mathrm{kg},-214 \mathrm{pg} / \mathrm{mg} \mathrm{Cr}-14 \%$ vs $-329 \mathrm{pg} / \mathrm{mg} \mathrm{Cr}-35 \% ; \mathrm{P}=$ 0.2 ANOVA), although this was not statistically significant (Figure 3).

We had only 2 cases of CAL and could not evaluate the 8-iso-PG level in those patients.

\section{Discussion}

Cardiovascular disease is related to increased systemic OS; established risk factors of systemic vascular disease, such as diabetes, have been associated with elevated levels of markers of OS. Measurement of the urinary excretion of 8-iso-PG has been characterized as a method of investigating lipid peroxidation in vivo and has been shown to reflect enhanced OS, regardless of the underlying pathophysiological trigger. Systemic vascular disease in which endothelial dysfunction is postulated on the basis of recent data has been reported to be associated with increased 8-iso-PG levels. ${ }^{3-5}$

Palombo et al demonstrated that hypercholesterolemic animals had increased circulating levels of 8-iso-PG and increased deposition on the intimal surface of vessels $!^{2}$ The association between increased circulating levels and increased intimal deposition of 8-iso-PG supports the pathogenetic role of 8 -iso-PG in vascular damage. This finding leads to a hypothesis of intimal disease as a dynamic process involving the arterial wall in the early stages of atherosclerosis, where the morphologic abnormality may be related to possibly reversible biochemical changes more than to permanent structural abnormalities ${ }^{12}$

Kato et al reported that baseline percent flow-mediated vasodilation (FMD) was lower and the baseline 8-iso-PG level higher in smokers than in nonsmokers, that \%FMD decreased and the 8-iso-PG level increased in nonsmokers to the levels in smokers after exposure to $30 \mathrm{~min}$ of passive smoking, and the \%FMD negatively correlated with the 8iso-PG level 13 It has already been established that vascular endothelial function is impaired and plasma lipid peroxidation products are elevated in nonsmokers exposed to passive smoke! ${ }^{3}$ This data showed of 8 -iso-PG products immediately after exposure to OS. Our results demonstrate that isoprostane products are present in the acute phase of KD. In our group of KD patients, the urinary 8-iso-PG level was higher than that of healthy subjects, which suggests that in the acute phase of KD there is endothelial peroxidation, which may be associated with increased OS in this setting.
Moreover, the normal range of 8 -iso-PG in childhood is less than $650 \mathrm{pg} / \mathrm{mg} \mathrm{Cr}$ and our results showed that the 8iso-PG level in children was higher than that in healthy adults.14-16 However, we did not differentiate between infants and older children. The 8-iso-PG level in the KD patients was also higher than in those with a febrile disease caused by a mild viral infection. The 8 -iso-PG level in patients with a severe bacterial infection may be higher than in those patients.

We observed that IVIG reduced the 8-iso-PG levels in patients with acute phase of KD who had significantly increased 8-iso-PG levels before treatment, which suggests that IVIG may be an anti-oxidant, as are vitamins E and C.

Measurement of the 8-iso-PG concentration has proven to be valuable in assessing OS in vivo, because it is a specific product of lipid peroxidation ${ }^{15-18}$ Although an increase in the 8-iso-PG level is indirect evidence of endothelial dysfunction, 8-iso-PG is a specific marker of oxidative injury in vasculitis ${ }^{19-22}$ Our study demonstrated that OS activation plays an important role in the pathological process of the acute phase of $\mathrm{KD}$. In addition, 8-iso-PG is also a reliable marker of OS in the acute phase of KD and may be a sensitive marker of the effects of IVIG therapy.

Interestingly, our results showed that there is no correlation between 8-iso-PG and inflammatory markers such as CRP, WBC count and ESR. This observation may indicate that 8 -iso-PG is an independent parameter of endothelial injury in the acute phase of KD. Furthermore, we hypothesize that IVIG may have antioxidative effects that prevent the generation of 8-iso-PG.

We had 2 patients with coronary artery abnormalities, but only 2 cases are too few to assess OS in patients with CAL and further study of such patients should be needed.

In a recent study, 8-iso-PG promoted platelet aggregation and induced platelet adhesion. Moreover, 8-iso-PG is a powerful constrictor of the vasculature and so increased generation of bioactive 8-iso-PG may be responsible for damage.

Another important point is that measurement of urinary 8 -iso-PG is a totally noninvasive method and is superior to measurement of 8-iso-PG in serum, because urinary 8-iso$\mathrm{PG}$ is a stable molecule . $^{2-24}$

Our data showed that measurement of an OS marker could represent oxidative capacity in vascular disease. Further studies are needed to evaluate 8-iso-PG against antioxidants such as vitamin $\mathrm{C}$ in acute $\mathrm{KD}$. 


\section{Conclusions}

Our study revealed OS provokes vasculitis in $\mathrm{KD}$, the activation of which was reduced by IVIG administration. We conclude that the urinary 8 -iso-PG level is a sensitive and useful marker of the effectiveness of IVIG therapy in the acute phase of KD.

\section{Acknowledgments}

This study was partly supported by a Research Grant from Ministry of Health, Labor and Welfare Health and Labor Sciences Research on Publicly Essential Drug and Medical Devices (H18-020), entitled "Study of the Development and safety of artificial polyclonal immunoglobulin for treatment of vasculitis syndrome" (Chief Investigator; Kazuo Suzuki, MD, Chiba University).

\section{References}

1. Maytin M, Leopold J, Loscalzo J. Oxidant stress in the vasculature. Curr Atheroscler Rep 1999; 1: 156-164.

2. Vassalle C, Petrozzi L, Botto N, Andreassi MG, Zucchelli GC. Oxidative stress and its association with coronary artery disease and different atherogenic risk factors. J Intern Med 2004; 256: 308-315.

3. Davì G, Ciabattoni G, Consoli A, Mezzetti A, Falco A, Santarone S, et al. In vivo formation of 8-iso-prostaglandin $\mathrm{F} 2 \alpha$ and platelet activation in diabetes mellitus: Effects of improved metabolic control and vitamin E supplementation. Circulation 1999; 99: 224-229.

4. Davi G, Alessandrini P, Mezzetti A, Minotti G, Bucciarelli T, Costantini $\mathrm{F}$, et al. In vivo formation of 8-epi-prostaglandin $\mathrm{F} 2 \alpha$ is increased in hypercholesterolemia. Arterioscler Thromb Vasc Biol 1997; 17: 2309-2315.

5. Morrow JD, Frei B, Longmire AW, Gaziano JM, Lynch SM, Shyr Y, et al. Increased in circulating products of lipid peroxidation (F2-isoprostanes) in smokers: Smoking as a cause of oxidative damage. $N$ Engl J Med 1995; 332: 1198-1203.

6. Reilly M, Delanty N, Lawson JA, FitzGerald GA. Modulation of oxidant stress in vivo in chronic cigarette smokers. Circulation 1996; 94: $19-25$

7. Morrow JD, Roberts LJ. The isoprostanes: Current knowledge and directions for future research. Biochem Pharmacol 1996; 51: 1-9.

8. Maury CPJ, Salo E, Pelkonen P. Circulating interleukin-1 in patients with Kawasaki disease. N Engl J Med 1988; 319: 1670-1671.

9. Furukawa S, Matsubara T, Jujoh K, Yone K, Sugawara T, Sasai K, et al. Peripheral blood monocyte/macrophage and serum tumor necrosis factor in Kawasaki disease. Clin Immunol Immunopathol 1988; 48: $247-251$.
10. Rowley AH, Shulman ST, Preble OT, Poiesz BJ, Ehrlich GD, Sullivan JR. Serum interferon concentration and retroviral serology in Kawasaki syndrome. Pediatr Infect Dis J 1988; 7: 663-665.

11. Tsuji K. Soluble intercellular adhesion molecule-1 levels in sera of patients with Kawasaki disease. Jpn J Allergol 1992; 41: 1507-1514.

12. Carlo P, Valter L, Tiziana S. Oxidative stress, F-isoprostanes and endothelial dysfunction in 2 hypercholesterolemia. Cardiovasc Res 1999; 44: 474-476.

13. Kato T, Inoue T, Morooka T, Yoshimoto N, Node K. Short-term passive smoking causes endothelial dysfunction via oxidative stress in nonsmoker. Can J Physiol Pharmacol 2006; 84: 523-529.

14. Ahola T, Fellman V, Kjellmer I, Raivio KO, Lapatto R. Plasma 8isoprostane is increased in preterm infants who develop bronchopulmonary dysplasia or periventricular leukomalasia. Pediatr Res 2004; 56: $88-93$.

15. Pratico D, Lawson JA, Fitzgerald GA. Cyclooxygenase-dependent formation of the isoprostan, 8-epi prostaglandine F2 $\alpha$. J Biol Chem 1995; 270: 9800-9808.

16. Roberts LJ, Marrow JD. Novel markers of endogenous lipid peroxidation and potential mediators of oxidant injury. Ann NY Acad Sci 1994; 744: 237-242.

17. Klein T, Reutter F, Schweer H, Seyberth HW, Nüsing RM. Generation of the isoprostane 8-epi-prostaglandin F2alpha in vitro and in vivo via the cyclooxygenases. J Pharmacol Exper Ther 1997; 282: $1658-$ 1665.

18. Fukunaga M, Makita N, Roberts LJD, Morrow JD, Takahashi K, Badr KF. Evidence for the existence of F2-isoprostane receptors on rat vascular smooth muscle cell. Am J Physiol 1993; 264: C1619C1624.

19. Cracowski JL, Devillier P, Durand T, Stanke-Labesque F, Bessard G Vascular biology of the isoprostanes. J Vasc Res 2001; 38: 93-103.

20. Vassalle C, Petrozzi L, Botto N, Andreassi MG, Zucchelli GC. Oxidative stress and its association with coronary artery disease and different atherogenic risk factors. J Intern Med 2004; 256: 308-315.

21. Schwedhelm E, Bartling A, Lenzen H, Tsikas D, Maas R, Brümmer $\mathrm{J}$, et al. Urinary 8-iso-prostaglandin F2alpha as a risk marker in patients with coronary heart disease: A matched case-control study. Circulation 2004; 109: 843-848.

22. Landmesser U, Spiekermann S, Dikalov S, Tatge H, Wilke R, Kohler $\mathrm{C}$, et al. Vascular oxidative stress and endothelial dysfunction in patients with chronic heart failure: Role of xanthine oxidase and extracellular superoxide dismutase. Circulation 2002; 106: 3037-3078.

23. Cracowski JL, Ploin D, Bessard J, Baguet JP, Stanke-Labesque F, Mallion JM, et al. Formation of isoprostanes in children with type IIa hypercholesterolemia. J Cardiovasc Pharmacol 2001; 38: 228-231.

24. Baraldi E, Ghiro L, Piovan V, Carraro S, Ciabattoni G, Barnes PJ, et al. Increased exhaled 8-isoprostane in childhood asthma. Chest 2003; 124: $25-31$. 